\title{
Wind observation around the tops of the midlatitude cirrus by the MU radar and Raman/Mie lidar
}

\author{
Masayuki K. Yamamoto ${ }^{1}$, Toyohisa Kishi ${ }^{1}$, Takuji Nakamura ${ }^{1}$, Noriyuki Nishi ${ }^{2}$, \\ Mamoru Yamamoto $^{1}$, Hiroyuki Hashiguchi ${ }^{1}$, and Shoichiro Fukao ${ }^{1,3}$ \\ ${ }^{1}$ Research Institute for Sustainable Humanosphere (RISH), Kyoto University, Uji, Kyoto 611-0011, Japan \\ ${ }^{2}$ Graduate School of Science, Kyoto University, Kyoto 606-8502, Japan \\ ${ }^{3}$ Fukui University of Technology, Fukui 910-8505, Japan
}

(Received August 27, 2008; Revised July 16, 2009; Accepted July 18, 2009; Online published August 7, 2009)

\begin{abstract}
Using a 46.5-MHz atmospheric radar referred to as the MU radar (MUR) and a Raman/Mie lidar installed at the Shigaraki $\left(34^{\circ} 51^{\prime} \mathrm{N}, 136^{\circ} 06^{\prime} \mathrm{E}\right)$, continuous wind motions around the tops of the midlatitude cirrus are described for the first time. The cloud system extended from the northeast to southwest $\left(35^{\circ} \mathrm{N}-50^{\circ} \mathrm{N}\right)$ along the eastward-moving trough and passed over Shigaraki in the nighttime between 5-6 November 2004. Cloud-top altitude observed by the lidar was located at $\sim 10.6 \mathrm{~km}$ around 1900 LST 5 November, then gradually descended to $\sim 8.4 \mathrm{~km}$ around 0500 LST 6 November. The westerly wind observed by MUR with 12-min and 150-m resolutions showed a rapid increase with altitude around the cloud tops and was almost always larger than $25 \mathrm{~m}$ $\mathrm{s}^{-1}$ above $\sim 1 \mathrm{~km}$ higher than the cloud tops. Objective reanalysis showed that a subtropical jet whose core existed to the south of Shigaraki caused a synoptic-scale vertical increase in the westerly wind around the cloud tops. Radiosondes observed a significant vertical increase of potential temperature (greater than $4 \mathrm{~K}$ within several hundred meters) around the cloud tops. MUR successfully observed fine time and altitude variations of winds which showed a good correspondence with the descending cloud tops.
\end{abstract}

Key words: Radar, lidar, cirrus.

\section{Introduction}

Cirriform clouds (cirrus, cirrostratus, cirrocumulus) existing in the upper troposphere consist almost entirely of ice particles (Houze, 1993) and play a significant role in regulating the radiation balance of the earth-atmosphere system (e.g., Liou, 1986). However, their optical properties and radiative effects are not sufficiently quantified due to a scarcity of observations. Lidars and cloud profiling radars have been used to quantify the microphysical properties of cirriform clouds (e.g., Whiteman et al., 2001; Mace et al., 2002). Knowledge of dynamical processes is important to an understanding of microphysical processes of clouds (e.g., Starr and Cox, 1985). Atmospheric radars which receive echoes from fluctuations of refractive index are useful for directly observing height profiles of vertical and horizontal winds both in clear and cloud regions (Fukao, 2007). Mesosphere-Stratosphere-Troposphere (MST) atmospheric radars (hereafter MST radars) to observe winds and turbulence up to the mesosphere are useful for observing uppertropospheric winds with high time and vertical resolutions (Kato, 2009). It has been shown that a combination of atmospheric radar and cloud profiling radar is useful for knowing dynamical processes in and around cirriform clouds (Yamamoto et al., 2008). However, cloud profiling radars tend to fail to detect cloud tops due to lack of sensitivity. Hence, a combination of MST radar and lidar is suitable for ob-

Copy right (C) The Society of Geomagnetism and Earth, Planetary and Space Sciences (SGEPSS); The Seismological Society of Japan; The Volcanological Society of Japan; The Geodetic Society of Japan; The Japanese Society for Planetary Sciences; TERRAPUB serving wind motions around cloud tops. In this study, continuous wind motions around the tops of midlatitude cirriform clouds are presented using the MST radar operated at the VHF band $(46.5 \mathrm{MHz})$ and the Raman/Mie lidar. The case from 1800 LST 5 to 0600 LST 6 November 2004 at Shigaraki MU Observatory, Japan $\left(34^{\circ} 51^{\prime} \mathrm{N}, 136^{\circ} 06^{\prime} \mathrm{E}\right)$ is described.

\section{Data}

2.1 The middle and upper atmosphere (MU) radar

The middle and upper atmosphere radar (hereafter MUR) is a 46.5-MHz MST radar with an active phased array antenna (aperture of $8330 \mathrm{~m}^{2}$ ) and 1-MW peak output power (Fukao et al., 1985). Two observation modes were used for observing upper-tropospheric vertical and horizontal winds. One was a 5-beam mode which steered radar beams to vertical, northward, eastward, southward, and westward directions on a pulse-to-pulse basis. Four oblique beams had a zenith angle of $10^{\circ}$. Zonal (meridional) wind was computed using Doppler shifts observed by two symmetric radar beams in the zonal (meridional) direction. Another was a 1-beam mode in which the radar beam was pointed only in the vertical direction. By steering a radar beam only to the vertical direction, the signal-to-noise ratio (SNR) of the frequency power spectrum obtained by the 1beam mode improves $\sim 7 \mathrm{~dB}$ compared with that obtained by the 5-beam mode. Because a higher SNR contributes to a better estimation accuracy of the vertical wind whose amplitude is small (typically less than several tens of $\mathrm{cm}$ $\mathrm{s}^{-1}$ ), vertical wind was computed from a Doppler shift ob- 
served by the vertically-pointed radar beam of the 1-beam mode. In both observation modes, the vertical resolution was $150 \mathrm{~m}$. MUR was further operated with another 5-beam mode to make observations only in the lower troposphere (below $\sim 5 \mathrm{~km}$ ). Data obtained by this mode were not used for data analysis. The observation time of the 1-beam, 5beam, and a second 5-beam mode were $93 \mathrm{~s}, 82 \mathrm{~s}$, and $65 \mathrm{~s}$, respectively. To reduce small-scale wind fluctuations, three successive altitude profiles of vertical and horizontal wind in time, each of which was produced every $240 \mathrm{~s}$, were averaged to produce 12-min resolution data.

Using equation (13) of Yamamoto et al. (1988), an uncertainty of vertical wind was estimated. The value of coefficient $k$, which is listed in table 1 of Yamamoto et al. (1988) and used in the equation, was 0.38 . Using the values of radar wavelength $(6.45 \mathrm{~m})$, observation time (93 s), number of incoherent integrations ( 3 times), and $k$, the uncertainty of vertical wind was estimated to be $0.01-0.04 \mathrm{~m} \mathrm{~s}^{-1}$ for a spectral width of $0.1-1.0 \mathrm{~m} \mathrm{~s}^{-1}$.

\subsection{Raman/Mie lidar}

Previous studies have shown that Raman lidars are useful tools by which to observe microphysical properties of cirrus clouds (e.g., Whiteman et al., 2001, 2004). A Raman/Mie lidar (hereafter lidar) installed at the Shigaraki MU Observatory was operated at a transmitted wavelength of $532.25 \mathrm{~nm}$, pulse repetition frequency of $50 \mathrm{~Hz}$, and pulse energy of $600 \mathrm{~mJ}$. The altitude profile of signal intensity received by elastic channel (hereafter $\left.P_{\mathrm{el}}(z)\right)$ and those of two pure rotational Raman (531.14 and $528.76 \mathrm{~nm}$ ) channels were obtained at time and vertical intervals of $1 \mathrm{~min}$ and $72 \mathrm{~m}$, respectively. $z$ denotes the range from the lidar. Using pure rotational Raman signals, we computed Raman reference signal (hereafter $P_{\text {ref }}(z)$ ). For computation of $P_{\text {ref }}(z)$, see Behrendt et al. (2004).

Altitude profiles of the cloud backscatter coefficient (hereafter $\left.\beta_{\mathrm{c}}(z)\right)$ were computed to determine cloud borders. First, altitude profiles of the backscatter ratio (hereafter $R(z)$ ), a ratio of total signal intensity scattered by clouds and molecules to that scattered by air molecules, was computed. $P_{\mathrm{el}}(z)$ and $P_{\mathrm{ref}}(z)$ were calibrated in order that $R(z)$ at altitudes higher than cloud tops, where scattering from clouds and aerosols was negligible, equaled 1. Because the wavelengths of the elastic and two pure rotational Raman signals were almost identical, wavelength dependency of extinction was negligible for computing $R(z)$. Second, the altitude profile of the molecular backscatter coefficient (hereafter $\beta_{\text {air }}(z)$ ) was computed using the altitude profile of the number density of molecules (hereafter $\left.N_{\text {air }}(z)\right)$ and scattering cross section per single molecule. $N_{\text {air }}(z)$ was computed by averaging pressure and temperature profiles observed by radiosondes launched at Shigaraki at 2017 LST 5, 0016 LST 6, and 0420 LST 6 November 2004. The scattering cross section per single molecule was computed by equation (2) of Bodhaine et al. (1999). Finally, $\beta_{\mathrm{c}}(z)$ was computed by $\beta_{\mathrm{c}}(z)=(R(z)-1) \beta_{\text {air }}(z)$.

The threshold value of $\beta_{\mathrm{c}}$ for determining cloud borders was selected to satisfy that (1) the threshold value is small enough to detect a small increase of $\beta_{\mathrm{c}}$ due to the presence of cloud particles, and (2) the threshold value is large enough to avoid any misestimation of cloud borders due to $\beta_{\mathrm{c}}$ fluctuations caused by uncertainty of the received

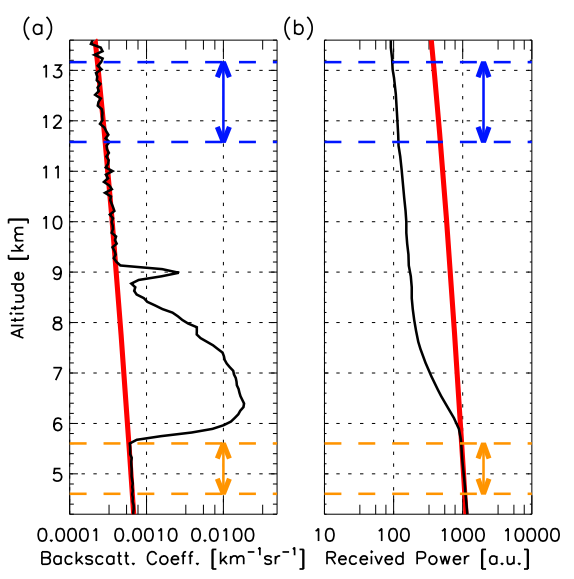

Fig. 1. (a) Altitude profile of $\beta_{\mathrm{c}}+\beta_{\text {air }}$ observed by the lidar (black curve) and $\beta_{\text {air }}$ calculated from radiosondes (red curve). (b) Altitude profile of $z^{2} P_{\text {ref }}(z)$ (black curve) and $K_{\rho} N_{\text {air }}(z)$ (red curve). Data presented are averaged over the period of 0224-0236 LST 6 November 2004. Vertical resolution of profiles in (a) and (b) are $72 \mathrm{~m}$ and $216 \mathrm{~m}$, respectively. Orange arrow shows altitudes used for computing $K_{\rho}$. Blue arrow shows altitudes used for computing $R(z)$ and $\tau$. $\tau$ was estimated to be 0.65 .

signals. Threshold values were changed to select the best one that satisfied both conditions (1) and (2). As a result, regions where $\beta_{\mathrm{c}}>2.0 \times 10^{-4} \mathrm{~km}^{-1} \mathrm{sr}^{-1}$ were identified as cloud. Note that lowering the threshold value of $\beta_{\mathrm{c}}$ to $1.0 \times 10^{-4} \mathrm{~km}^{-1} \mathrm{sr}^{-1}$ did not significantly change our findings in this study. Figure 1(a) is an example to show altitude profiles of $\beta_{\mathrm{c}}(z)+\beta_{\text {air }}(z)$ observed by the lidar and $\beta_{\text {air }}(z)$ calculated from radiosondes. Except for cloud altitudes $(5.6-9.2 \mathrm{~km})$, values of $\beta_{\mathrm{c}}(z)+\beta_{\text {air }}(z)$ were almost the same as $\beta_{\text {air }}(z)$. This agreement shows that cloud borders are able to be determined using $\beta_{\mathrm{c}}(z)$ observed by the lidar.

Cloud optical depth (hereafter $\tau$ ) was used to classify the kind of observed clouds. Because $P_{\text {ref }}$ after rangedivergence correction $\left(z^{2} P_{\text {ref }}(z)\right)$ depends on $N_{\text {air }}(z)$ and light attenuation by clouds and molecules, $\tau$ was computed using $P_{\text {ref }}(z)$ attenuation within clouds. First, a constant value of $K_{\rho}$ was determined so that $z^{2} P_{\text {ref }}(z)$ and $K_{\rho} N_{\text {air }}(z)$ have the same amplitudes at $0-1 \mathrm{~km}$ below cloud-bottom altitude. Second, a signal attenuation of $z^{2} P_{\text {ref }}(z)$ by clouds and molecules (hereafter $P_{\text {att }}$ ) was estimated by $P_{\text {att }}=$ $z^{2} P_{\text {ref }}(z) /\left(K_{\rho} N_{\text {air }}(z)\right)$ at altitudes above the cloud tops. Finally, using $P_{\text {att }}, \tau$ was computed. To compute attenuation by molecules, the altitude profile of molecular extinction coefficient was computed using $\beta_{\text {air }}(z)$. Figure $1(b)$ is an example to show altitude profiles of $z^{2} P_{\text {ref }}(z)$ and $K_{\rho} \rho(z)$. Within cloud altitudes (5.6-9.2 km), due to scattering and absorption by cloud particles, $z^{2} P_{\text {ref }}(z)$ showed a sharp decrease as compared with $K_{\rho} \rho(z)$.

\subsection{Objective reanalysis}

Wind and temperature obtained by National Centers for Environmental Prediction/National Center for Atmospheric Research (NCEP/NCAR) reanalysis (Kistler et al., 2001) were used to show their synoptic-scale spatial distributions. Horizontal and time resolutions of NCEP/NCAR reanalysis are $2.5^{\circ}$ and $6 \mathrm{~h}$, respectively. At standard pressure levels (e.g., 100, 150, 200, 250, 300, $400 \mathrm{hPa}$ ), NCEP/NCAR reanalysis produces temperature and wind data. 


\section{Results and Discussion}

First of all, synoptic-scale wind and temperature distributions are presented. Figure 2 shows a latitude-altitude plot of zonal wind and potential temperature (hereafter $\Theta$ ) along the longitude of Shigaraki $\left(135^{\circ} \mathrm{E}\right)$ at $2100 \mathrm{LST} 5$ November 2004 obtained by NCEP/NCAR reanalysis. A subtropical jet was seen around $300-100 \mathrm{hPa}$. The westerly wind was maximum (larger than $50 \mathrm{~m} \mathrm{~s}^{-1}$ ) around $30.0-32.5^{\circ} \mathrm{N}$. Shigaraki $\left(35^{\circ} \mathrm{N}\right)$ was northward of the core of the subtropical jet. The westerly wind at $35^{\circ} \mathrm{N}$ showed a larger increase with altitude above $\sim 300 \mathrm{hPa}$ than below and was larger than $25 \mathrm{~m} \mathrm{~s}^{-1}$ above $300 \mathrm{hPa}(\sim 9.3 \mathrm{~km})$. At $35.0^{\circ} \mathrm{N}, \Theta$ also showed a larger vertical gradient above $300 \mathrm{hPa}$ than below. At $37.5-45.0^{\circ} \mathrm{N}$, the westerly wind was larger than $20 \mathrm{~m} \mathrm{~s}^{-1}$ at $\sim 400-200 \mathrm{hPa}$ due to the presence of trough.

Next, variations of cloud tops are presented. Figure 3(a) shows a time-altitude plot of $\beta_{\mathrm{c}}$ observed by the lidar. Cloud-top altitude was located at $\sim 10.6 \mathrm{~km}$ around 1900 LST 5 November, then gradually descended to $\sim 8.4 \mathrm{~km}$ around 0500 LST 6 November. $\tau$ observed by the lidar, ranging from 0.06 to 1.58 with an average of 0.60 (not shown), indicates that most of the clouds at Shigaraki were opaque cirrus having $\tau$ of 0.3-3.0 (Lynch et al., 2002). Infrared images observed by the GOES-9 weather satellite and synoptic-scale meteorological fields seen in NCEP/NCAR reanalysis showed that a cloud system, extended from the northeast to southwest $\left(35^{\circ} \mathrm{N}-50^{\circ} \mathrm{N}\right)$ along the eastward-moving trough, passed over Shigaraki in the nighttime between 5-6 November.

Variations of zonal winds at Shigaraki are presented. Figure 3(b) shows a time-altitude plot of zonal wind observed by MUR. The westerly wind was almost always smaller than $25 \mathrm{~m} \mathrm{~s}^{-1}$ below the cloud tops. At several hundred meters above the cloud tops, the westerly wind showed a rapid increase with altitude, and was almost always larger than $25 \mathrm{~m} \mathrm{~s}^{-1}$ above altitudes $\sim 1 \mathrm{~km}$ higher than the cloud tops. The observed increase of westerly wind above the cloud tops was consistent with the presence of the subtropical jet, as seen in NCEP/NCAR reanalysis (see Fig. 2). However, the observed descent of the large westerly wind (larger than $25 \mathrm{~m} \mathrm{~s}^{-1}$ ) with time was not clear in NCEP/NCAR reanalysis between 2100 LST 5 and 0300 LST 6 November due to its coarse time and vertical resolutions (not shown). These results indicate that wind observations with high time and vertical resolutions are important to clarify wind variations in and around upper-tropospheric cirriform clouds.

Variations of vertical wind at Shigaraki are presented. Figure 3(c) shows a time-altitude plot of the vertical wind. Though an upward wind of greater than $0.075 \mathrm{~m} \mathrm{~s}^{-1}$ was frequently observed in the cirrus during 1800-2024 LST 5 and 0448-0600 LST 6 November, this upward wind was not continuous during the observational period. Both upward and downward winds in the clouds were small (did not frequently exceed $0.15 \mathrm{~m} \mathrm{~s}^{-1}$ ). These results suggest that the resolutions of the dataset $(12 \mathrm{~min}$ and $150 \mathrm{~m})$ were not enough to detect the small-scale turbulence within cirriform clouds, which significantly influences condensation, evaporation, and particle spectra (see section 17 of Lynch et al., 2002). The small vertical increase of observed $\Theta$ in the clouds (less than $2 \mathrm{~K} \mathrm{~km}^{-1}$ ) suggests the presence of airmass mixing by turbulence (see Fig. 4). Fine-scale

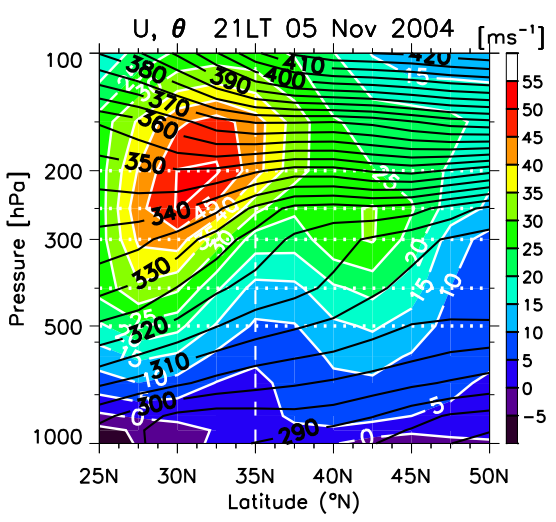

Fig. 2. Latitude-altitude plots of zonal wind (white contour with colored) and $\Theta$ (black contour) along $135^{\circ} \mathrm{E}$ at 2100 LST 5 November 2004.

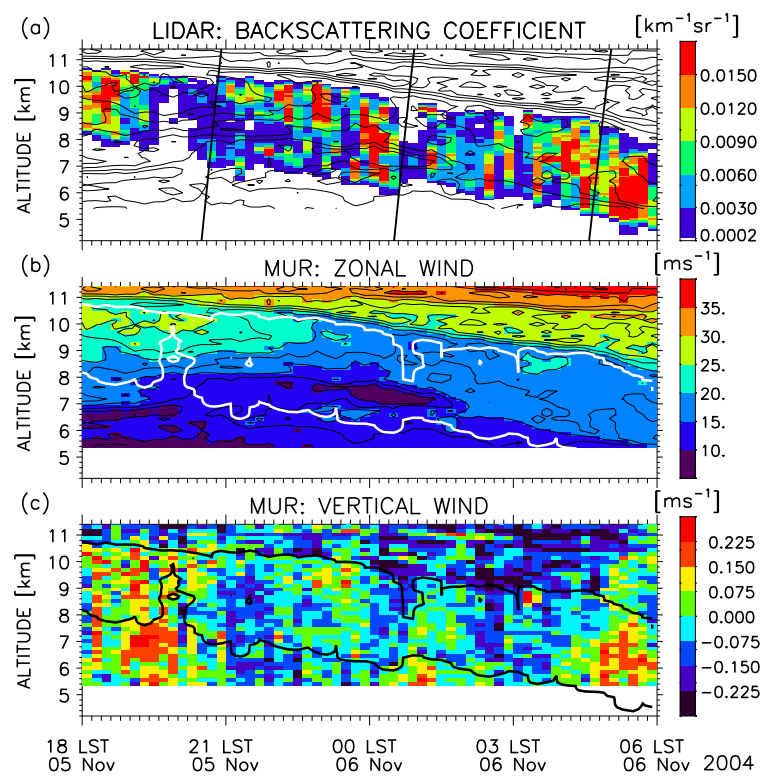

Fig. 3. Colored show time-altitude plot of (a) $\beta_{\mathrm{c}}$, (b) zonal wind, and (c) vertical wind from 1800 LST 5 to 0600 LST November 2004. Three thick curves in (a) indicate the altitudes of radiosondes. Black solid curve in (a) indicates zonal wind. White curve in (b) and black curve in (c) indicate the cloud border.

variations of vertical wind and turbulence in clouds will be treated in detail in future studies.

Variations of $\Theta$ observed around the cloud tops are presented. Figure 4 shows altitude profiles of $\Theta$ observed by radiosondes. $\Theta$ showed a large vertical gradient around cloud tops (greater than $4 \mathrm{~K}$ within several hundred meters; see Figs. 3(a) and 4). The lowest altitude where $\Theta$ rapidly increased with altitude located at $10.3 \mathrm{~km}$ ( $\Theta$ was $\sim 325$ $\mathrm{K}), 9.6 \mathrm{~km}(\sim 323 \mathrm{~K})$, and $8.6 \mathrm{~km}(\sim 318 \mathrm{~K})$ around 2024 2100 LST 5, 0024-0100 LST 6, and 0436-0500 LST 6 November, respectively. Because $\Theta$ at $35^{\circ} \mathrm{N}, 135^{\circ} \mathrm{E}$ seen in NCEP/NCAR reanalysis showed a larger vertical gradient above $300 \mathrm{hPa}$ (see Fig. 2), the observed vertical increase of $\Theta$ around the cloud tops was consistent with synopticscale conditions.

Finally, possible reasons for the descent of cloud-top altitude are described. Lapse-rate tropopause was $10.3 \mathrm{~km}$, $13.1 \mathrm{~km}$, and $15.7 \mathrm{~km}$ for the radiosonde soundings at 2017 LST 5, 0017 LST 6, and 0420 LST 6 November, 


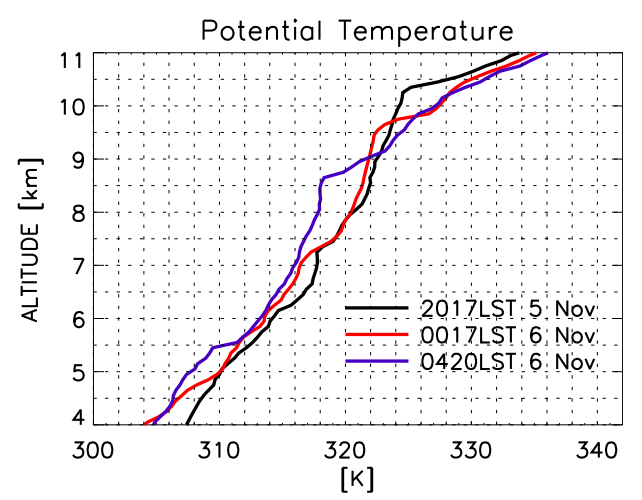

Fig. 4. Altitude profiles of $\Theta$ observed by radiosondes launched at 2017 LST 5 (black), 0017 LST 6 (red), and 0420 LST 6 November 2004 (blue).

respectively (not shown). This upward displacement of tropopause altitude did not agree with the descent of cloudtop altitude. Though the coarser vertical and time resolutions of NCEP/NCAR reanalysis can cause discrepancy from observations, it showed a similar tropopause variation as the observed one. From 1500 LST 5 to 0300 LST 6 November, the eastward-moving trough extended the midlatitudinal tropopause region southward and produced a higher tropopause pressure at $35^{\circ} \mathrm{N}, 135^{\circ} \mathrm{E}(\sim 210-220 \mathrm{hPa}$ or $\sim 11.3-11.7 \mathrm{~km}$ ). At 0900 and 1500 LST 6 November, tropopause pressure at $35^{\circ} \mathrm{N}, 135^{\circ} \mathrm{E}$ became lower ( $\sim 142.5 \mathrm{hPa}$ or $\sim 14.1 \mathrm{~km}$ ) as the subtropical tropopause region extended northward.

Because the lidar observed the clouds only over Shigaraki, advection is expected to play a role in the observed descent of cloud-top altitude. If the cloud top was higher (lower) in the eastern (western) side and this cloud-top distribution did not change with time, it is possible that the lidar observed the descent of cloud-top altitude with time. Variation in the vertical wind is also a candidate to explain the observed descent of cloud tops. Though an upward wind of greater than $0.075 \mathrm{~m} \mathrm{~s}^{-1}$ was frequently observed in the cirrus during 1800-2024 LST 5 November, this upward wind was not continuous from 2024 LST 5 to 0448 LST 6 November (see Fig. 3(c)). If MUR observed vertical wind behaviors associated with the eastward-moving trough (upward wind in the east of the trough; see figure 6.12 of Holton, 2004), it is possible that the absence of large-scale upward wind contributed to the larger descent of cloud-tops during their eastward advection, which caused the observed descent of cloud tops at Shigaraki. Further case studies by observations and numerical models would contribute to a clarification of factors which determine cloud-top altitude.

\section{Summary}

Using MUR and the Raman/Mie lidar, continuous wind motions around tops of midlatitude cirrus are described. The cloud system extended from the northeast to southwest $\left(35^{\circ} \mathrm{N}-50^{\circ} \mathrm{N}\right)$ along the eastward-moving trough and passed over Shigaraki in the nighttime between 5-6 November 2004. The cloud-top altitude observed by the lidar was located at $\sim 10.6 \mathrm{~km}$ around 1900 LST 5 November, then gradually descended to $\sim 8.4 \mathrm{~km}$ around 0500 LST 6 November. The westerly wind observed by MUR with 12- min and 150-m resolutions showed a rapid increase with altitude around the cloud tops, and was almost always larger than $25 \mathrm{~m} \mathrm{~s}^{-1}$ above $\sim 1 \mathrm{~km}$ higher than the cloud tops. NCEP/NCAR reanalysis showed that the subtropical jet whose core existed in the south of Shigaraki caused the synoptic-scale vertical increase in westerly wind around the cloud tops. Radiosondes observed the significant vertical increase of potential temperature (greater than $4 \mathrm{~K}$ within several hundred meters) around the cloud tops. Such features are able to be observed only by MST radars, which are able to observe the upper-tropospheric wind with high vertical and time resolutions. Using wind observation by MUR, further cases are currently studied.

Acknowledgments. MUR belongs to and is operated by the Research Institute for Sustainable Humanosphere, Kyoto University. NCEP/NCAR reanalysis data sets were provided from the anonymous ftp sites of the National Ocean and Atmospheric Administration/Climate Diagnostic Center. The present study was financially supported by Grants-in-Aids (16340139 and 19740293) of the Japanese Ministry of Education, Culture, Sports, Science, and Technology.

\section{References}

Behrendt, A., T. Nakamura, and T. Tsuda, Combined temperature lidar for measurements in the troposphere, stratosphere, and mesosphere, Appl. Opt., 43, 2930-2939, 2004.

Bodhaine, B. A., N. B. Wood, E. G. Dutton, and J. R. Slusser, On Rayleigh optical depth calculations, J. Atmos. Ocean. Technol., 16, 1854-1861, 1999.

Fukao, S., Recent advances in atmospheric radar study, J. Meteorol. Soc. Jpn., 85B, 215-239, 2007.

Fukao, S., T. Sato, T. Tsuda, S. Kato, K. Wakasugi, and T. Makihira, The MU radar with an active phased array system 1. Antenna and power amplifiers, Radio Sci., 20, 1155-1168, 1985.

Holton, J. R., An introduction to dynamic meteorology fourth edition, pp. 167, Elsevier Academic Press, Mass., 2004.

Houze, R. A., Jr., Cloud dynamics, pp. 15-19, Academic Press, San Diego, Calif., 1993.

Kato, S., Validity on radar observation of middle- and upper-atmosphere dynamics, Earth Planets Space, 61, 545-549, 2009.

Kistler, R. and coauthors, The NCEP-NCAR 50-year reanalysis: monthly means CD-ROM and documentation, Bull. Am. Meteorol. Soc., 82, 247267, 2001.

Liou, K.-N., Influence of cirrus clouds on weather and climate processes: A global perspective, Mon. Wea. Rev., 114, 1167-1199, 1986.

Lynch, D. K., K. Sassen, D. O'C. Starr, and G. Stephens, Cirrus, pp. 18, Oxford University Press, New York, 2002.

Mace, G. G., A. J. Heymsfield, and M. R. Poellot, On retrieving the microphysical properties of cirrus clouds using the moments of the millimeter-wavelength Doppler spectrum, J. Geophys. Res., 107, 4815, doi:10.1029/2001JD001308, 2002.

Starr, D. O'C. and S. K. Cox, Cirrus clouds. Part II: Numerical experiments on the formation and maintenance of cirrus, J. Atmos. Sci, 42, 26822694, 1985.

Whiteman, D. N. and coauthors, Raman lidar measurements of water vapor and cirrus clouds during the passage of Hurricane Bonnie, J. Geophys. Res., 106, 5211-5225, 2001.

Whiteman, D. N., B. Demoz, and Z. Wang, Subtropical cirrus cloud extinction to backscatter ratios measured by Raman lidar during CAMEX-3, Geophys. Res. Lett., 31, L12105, doi.10.1029/2004GL020003, 2004.

Yamamoto, M. and coauthors, Estimation error of spectral parameters of mesosphere-stratosphere-troposphere radars obtained by least squares fitting method and its lower bound, Radio Sci., 23, 1013-1021, 1988.

Yamamoto, M. K. and coauthors, Observation of particle fall velocity in cirriform cloud by VHF and millimeter-wave Doppler radars, J. Geophys. Res., 113, D12210, doi:10.1029/2007JD009125, 2008.

M. K. Yamamoto (e-mail: m-yamamo@rish.kyoto-u.ac.jp), T. Kishi, T. Nakamura, N. Nishi, M. Yamamoto, H. Hashiguchi, and S. Fukao 